\title{
Criação de Workshop de baixo custo em RFID utilizando a plataforma de prototipagem Arduino com foco no ensino de eletromagnetismo para estudantes do Ensino Médio.
}

\author{
Henrique Dal Mora Rosendo da Silva, Luiz A. Fabri Junior, Marli de Freitas Gomes Hernandez
}

\section{Resumo}

Este projeto tem como objetivo propor a inserção do microcontrolador Arduino em conjunto de antenas que compõem as diversas etiquetas RFID presentes no cotidiano dos estudantes, como nos cartões de transporte público, por exemplo, para assim desenvolver um kit de aprendizado em cima dos conteúdos de física que englobam conceitos da área de eletromagnetismo abordados no Ensino Médio. Com isso, foi proposto um cenário de estudo em cima do funcionamento de sistemas compostos pela tecnologia RFID, com base na aprendizagem significativa perante 0 fenômeno de propagação de ondas eletromagnéticas em antenas, fundamentado pelo conhecimento de eletromagnetismo que o aluno obtém ao longo de sua formação. A introdução do microcontrolador Arduino será feita em conjunto de um aplicativo desenvolvido na plataforma Android, para assim possibilitar uma maior interação dos alunos e professores com os conteúdos criados.

\section{Palavras-chave:}

Arduino, RFID, Educação Tecnológica.

\section{Introdução}

O projeto tem como principal objetivo estruturar conteúdos de física que englobam conceitos da área de eletromagnetismo desenvolvidos ao longo do ensino médio. Esses conceitos serão analisados com base na tecnologia de Rádio Frequência, mais especificamente em cima de dispositivos RFID. Serão desenvolvidas, dentre outras, as seguintes atividades:

1. Análise da forma de indução de corrente elétrica a partir de um campo magnético gerado por um leitor RFID em uma etiqueta composta por uma antena e um microchip integrados;

2. Estudo do funcionamento e arquitetura de modelos ideais de antenas utilizadas na indústria;

3. Elaboração de antenas em placas de circuito impresso (PCB) que possam atuar como etiquetas RFID passivas em uma determinada frequência;

Será feito um estudo do funcionamento desses componentes, e como o eletromagnetismo pode ser explorado a partir da comunicação entre um leitor e uma etiqueta RFID passiva, também conhecida como um transpônder indutivo. Esse procedimento de aprendizagem e de práticas experimentais será feito em cima da plataforma de prototipagem Arduino, a qual englobará uma interface de comunicação com um dispositivo Android, através de um aplicativo desenvolvido para esse fim.

\section{Resultados e Discussão}

Uma primeira análise prática apresentada aos estudantes têm como objetivo introduzir o conceito de antenas em loop e, com isso, os conhecimentos de indutância distribuída e capacitância e resistência parasitas. Com isso, um modelo simples de uma antena em loop quadrada é proposto, como mostrado nas figuras 1 e 2 .

Pelo modelo, e a confecção das placas em circuito impresso (PCB) das antenas, é possível realizar os processos de experimentação junto ao kit desenvolvido em Arduino, com auxílio do aplicativo Android. A indução de corrente na antena ocorre quando ela está em proximidade do módulo RFID. As medidas de corrente induzida são feitas diretamente nas entradas analógicas do microcontrolador, que, através de um módulo Bluetooth, é feita a comunicação com o aplicativo e, assim, é possível que o aluno observe e interaja com esses dados através de parâmetros variáveis como distância de leitura e variação da quantidade de loops na antena, por exemplo.

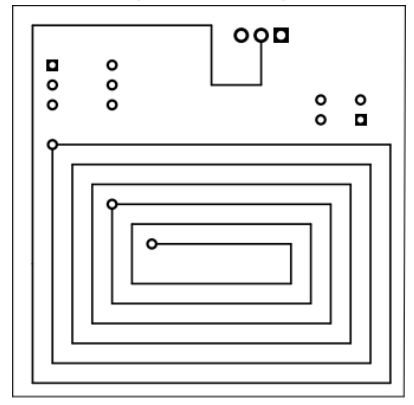

Figura 1.

Face superior da antena.

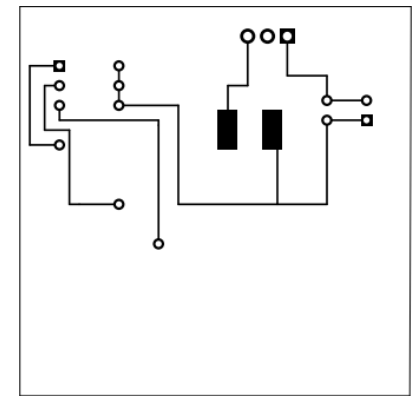

Figura 2.

Face inferior da antena

\section{Conclusão}

Através dos procedimentos propostos no kit desenvolvido, é proporcionado ao aluno um processo de aprendizagem significativa, onde ele, a partir de conhecimentos de eletromagnetismo adquiridos ao longo do ensino médio, aprende sobre conceitos relacionados à propagação de ondas eletromagnéticas em antenas. Isso tudo relacionado com a tecnologia RFID, amplamente utilizada ou presenciada no cotidiano de cada indivíduo, com o intuito de impulsionar o interesse desses pelos assuntos teóricos amplamente abordados.

\section{Agradecimentos}

Ao programa CNPq/PIBITI pelo financiamento do projeto de pesquisa.

${ }^{1}$ Balanis, C. A., Antenna Theory Analysis and Design, 2nd Ed., John Wiley \& Sons, New York, 1997. 